\title{
DÜBLIN
}

Technological University Dublin

ARROW@TU Dublin

2008-01-01

\section{Spatial Group Delay Patterns For Three Ultra Wideband Spline}

\section{Antennas}

\author{
Patrick McEvoy \\ Technological University Dublin, patrick.mcevoy@tudublin.ie \\ Matthias John \\ Technological University Dublin, matthias.john@tudublin.ie \\ Sergio Curto \\ Technological University Dublin, sergiocurtoramos@gmail.com
}

See next page for additional authors

Follow this and additional works at: https://arrow.tudublin.ie/engschececon

Part of the Electrical and Computer Engineering Commons

\section{Recommended Citation}

McEvoy, P. et al. (2008) Spatial group delay patterns for three ultra wideband spline antennas. IEEE Antennas and Propagation Society International Symposium, 2008. pp5-11. San Diego, 5-11 July, 2008, doi:10.1109/APS.2008.4619152

This Conference Paper is brought to you for free and open access by the School of Electrical and Electronic Engineering at ARROW@TU Dublin. It has been accepted for inclusion in Conference papers by an authorized administrator of ARROW@TU Dublin. For more information, please contact arrow.admin@tudublin.ie, aisling.coyne@tudublin.ie,gerard.connolly@tudublin.ie.

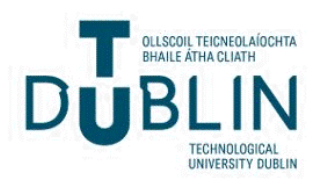


Authors

Patrick McEvoy, Matthias John, Sergio Curto, and Max Ammann

This conference paper is available at ARROW@TU Dublin: https://arrow.tudublin.ie/engschececon/40 


\title{
Spatial Group Delay Patterns for Three Ultra Wideband Spline Antennas
}

\author{
Patrick McEvoy*(1), Matthias John ${ }^{(2)}$, Sergio Curto ${ }^{(1)}$ and Max J Ammann ${ }^{(1,2)}$ \\ (1) Antennas \& High Frequency Research (AHFR) Group \\ (2) Centre for Telecommunications Value-chain Research (CTVR) \\ Dublin Institute of Technology, Kevin Street, Dublin 8, Ireland. \\ Email: Patrick.McEvoy@dit.ie
}

\section{Introduction}

The IEEE ultra wideband (UWB) standard includes both a multiple frequency carrier (MB-OFDM) and an impulse spectrum (DS-UWB) method, for which application antennas should be appropriately optimized. Small printed monopoles with outline features that can be defined by a Bézier-spline [1] have good matched impedance performance across the 3.1 - $10.6 \mathrm{GHz}$ band. For communications applications, an omni-directional pattern, where the gain pattern varies by less than $\pm 5 \mathrm{dBi}$, and a stable frequency-gain profile in the azimuth plane, allow for an even spatial coverage in all directions. In the case of an impulse system, any non-linear phase transfer performance in the antenna adds distortion to the transieved pulses therefore reducing the data rates. Contemporary UWB antenna gain performances are often presented across the whole spectrum using contour plots. This discloses more details and compliments the conventional sampled frequency polar plots that are more suited to narrow bandwidth antennas. In this paper, the approach is extended to a group delay pattern measurement which is more comprehensive than the traditional and limited boresight-only approach.

Fig 1 shows the three Bézier-spline shaped antennas, labeled "A," "B" \& "C," used here. The front of the printed monopoles were aligned in the measurement system to face the standardised $\mathrm{x}$-axis co-ordinate direction.

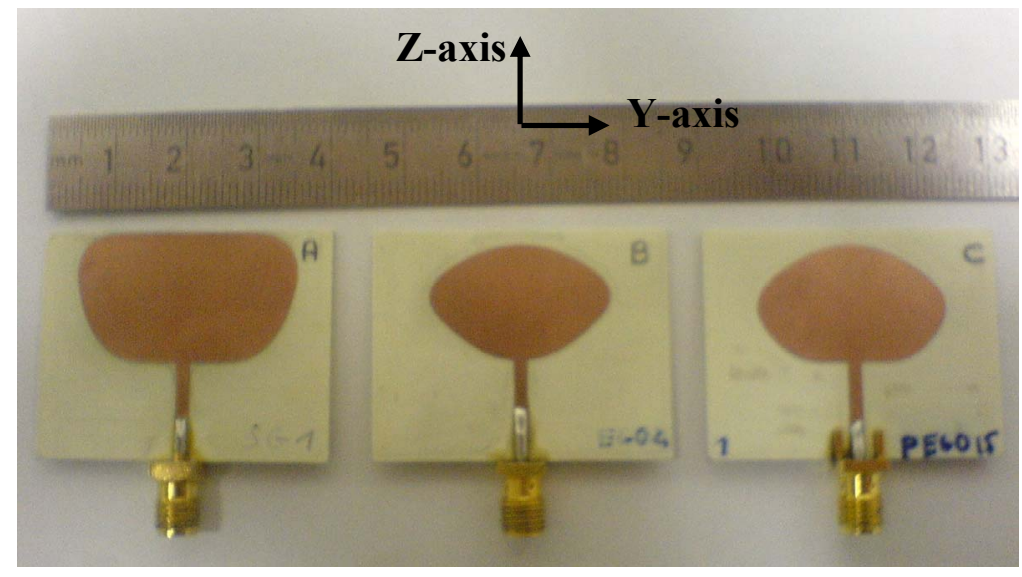

Fig. 1 Spline Antennas "A", "B" \& "C"

The rounded features of the spline antennas are a result of an Evolutionary Global Optimiser (EGO) process designed to enhance the matched bandwidth of the antennas. Each of microstrip geometies are less than $31 \mathrm{~mm}$ in height and additonal design details can be found in [1]. 


\section{Measurements}
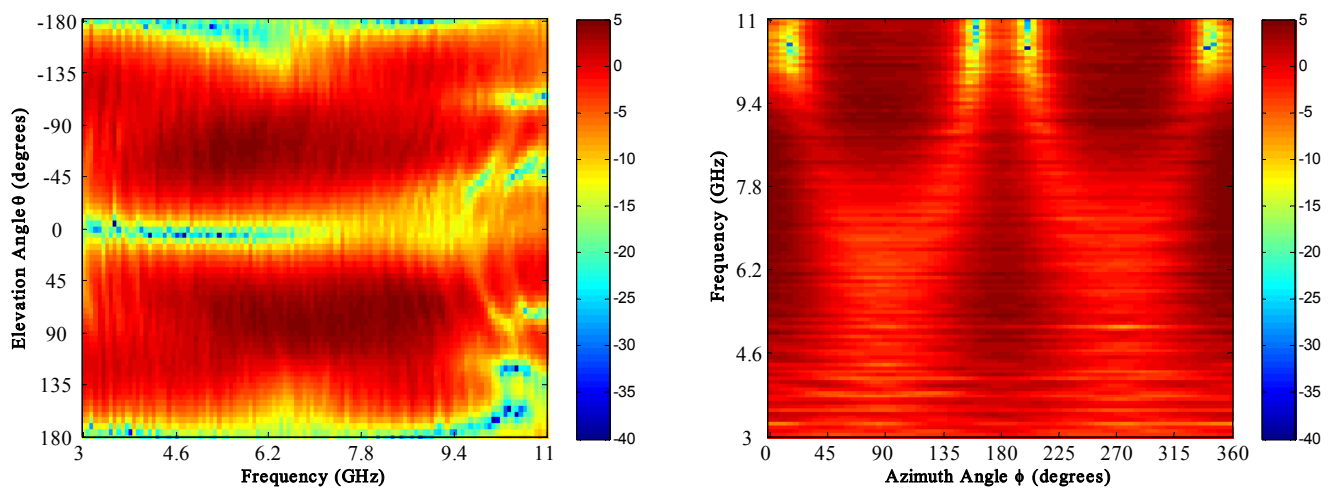

Fig. 2 Antenna "A" - Elevation \& Azimuth Planes E0-Polarization Gain
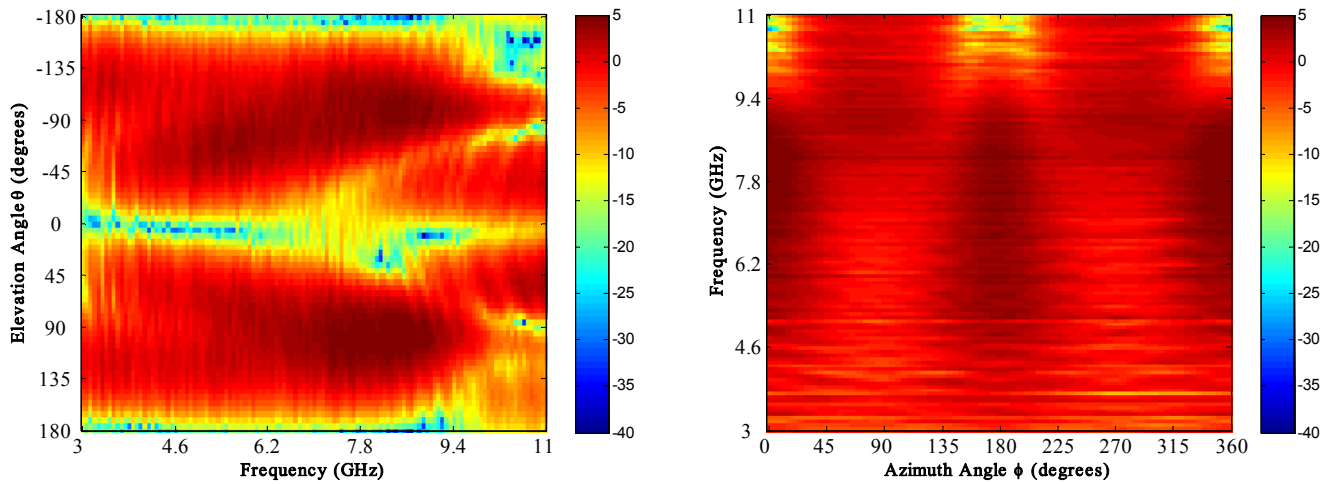

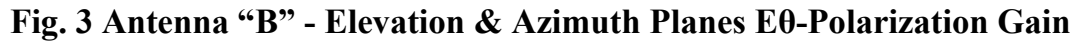
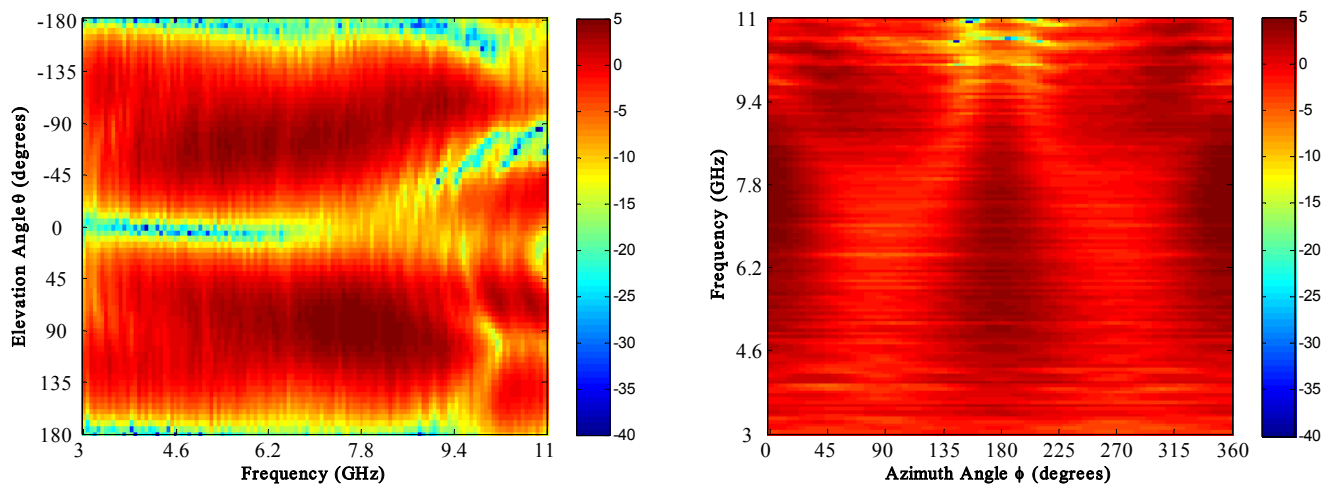

Fig. 4 Antenna "C" - Elevation \& Azimuth Planes E0-Polarization Gain

Fig. 2 to Fig. 4 show E $\theta$ polarization plots for the elevation plane $\left(\varphi=0^{\circ}\right)$ and the azimuth plane $\left(\theta=90^{\circ}\right)$ in the UWB spectrum of the three antennas. Generally, the elevation plots illustrate stable gain profiles in omni-directional sectors between the monopole vertical nulls in the UWB Bands A and B $(3.1-4.9 ; 4.9-6.0 \mathrm{GHz})$. In Band C $(6.0-8.1 \mathrm{GHz})$ the stable gain sector reduces slightly and in Band D $(6.0-8.1 ; 8.1-10.6 \mathrm{GHz})$ the nulls broaden to the front of antenna "A" and to 
the rear of antennas "B" \& "C". The azimuth planes exhibit more similarity across Bands $\mathrm{A}$ to $\mathrm{C}$, where the stable gain is higher in YZ-plane. In Band $\mathrm{D}$, the gains drop around the XZ-planes.

Fig. 5 to Fig. 7 illustrates the group delay performance of the antennas in azimuth plane. The group delay is defined as the negative derivative of the phase response with respect to frequency [2]. The group delay gives an indication of the time delay that the signal suffers in proportion to the wavelength dimensions on the antenna.

The network analyzer was set to measure the S21 phase and the antennas were connected to the reference ports 1 and 2 in three grouped pairs, namely; $\mathrm{AB}, \mathrm{BC}$ and $\mathrm{CA}$ respectively. The antennas were separated by a 0.6 meter distance in an anechoic environment and were aligned in the azimuth planes at $\varphi=0^{\circ}$ respectively. Completing each measurement in a constant direction equalized the propagation effect of the channel.

By combining each of the group delay measurements into a system of simultaneous equations, the individual effects of each antenna was extracted (analogous to the three antenna method [3]). Through inspection, the stratified group delay contours in bands $\mathrm{A}, \mathrm{B}$ and $\mathrm{C}$ shows good omni-directional stability for given frequencies.

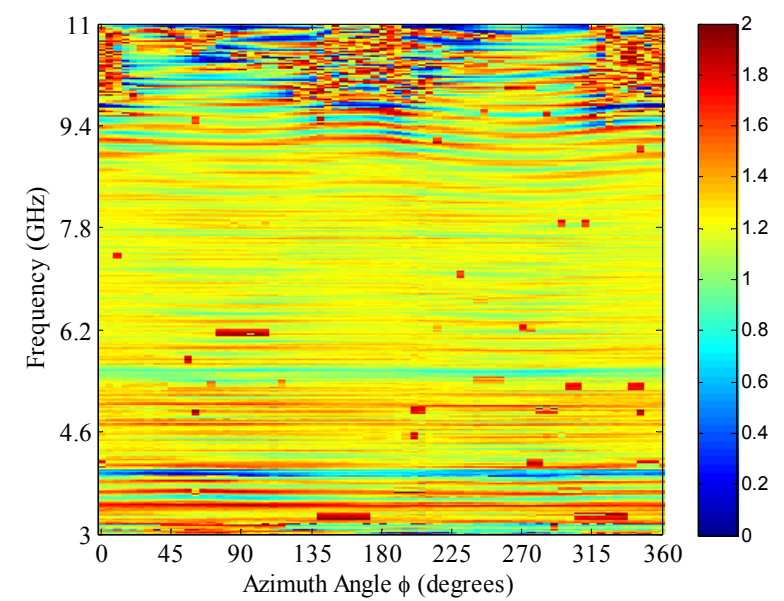

Fig. 5 Antenna A Azimuth Group Delay (ns)

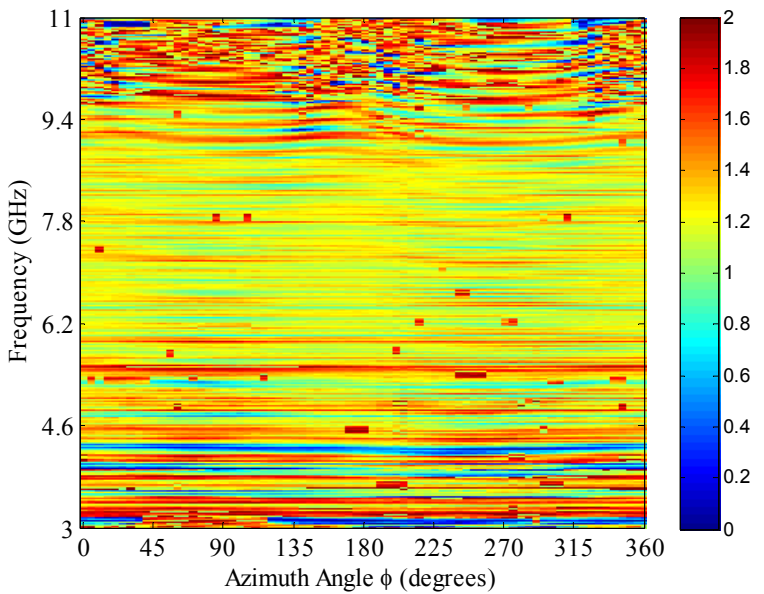

Fig. 7 Antenna B Azimuth Group Delay (ns)

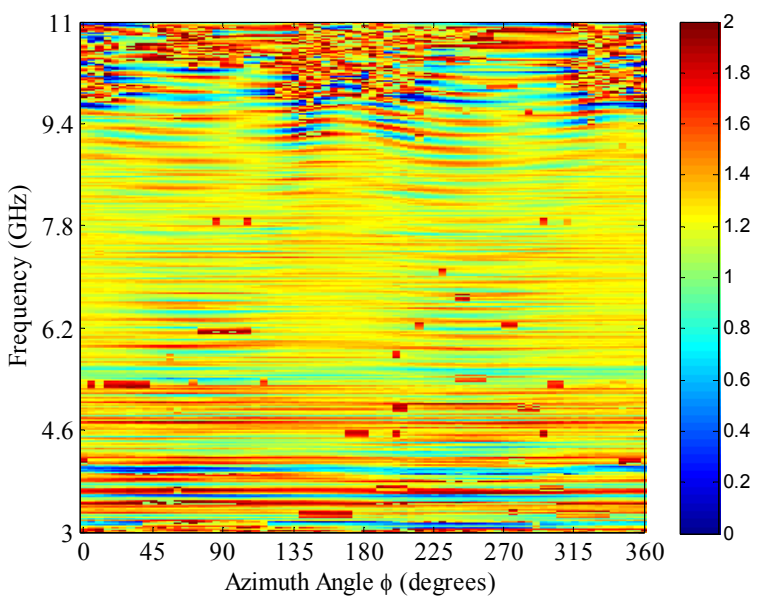

Fig. 6 Antenna C Azimuth Group Delay (ns) 
Although the group delay data was averaged using an 11 point smoothing function, artifacts remain in the plots which are evidence of systematic errors in the measurements. This is attributed to back-ground noise and repeat measurements are planned in a screened environment to remove this. The band D performance shows the strongest distortion in the scale range.

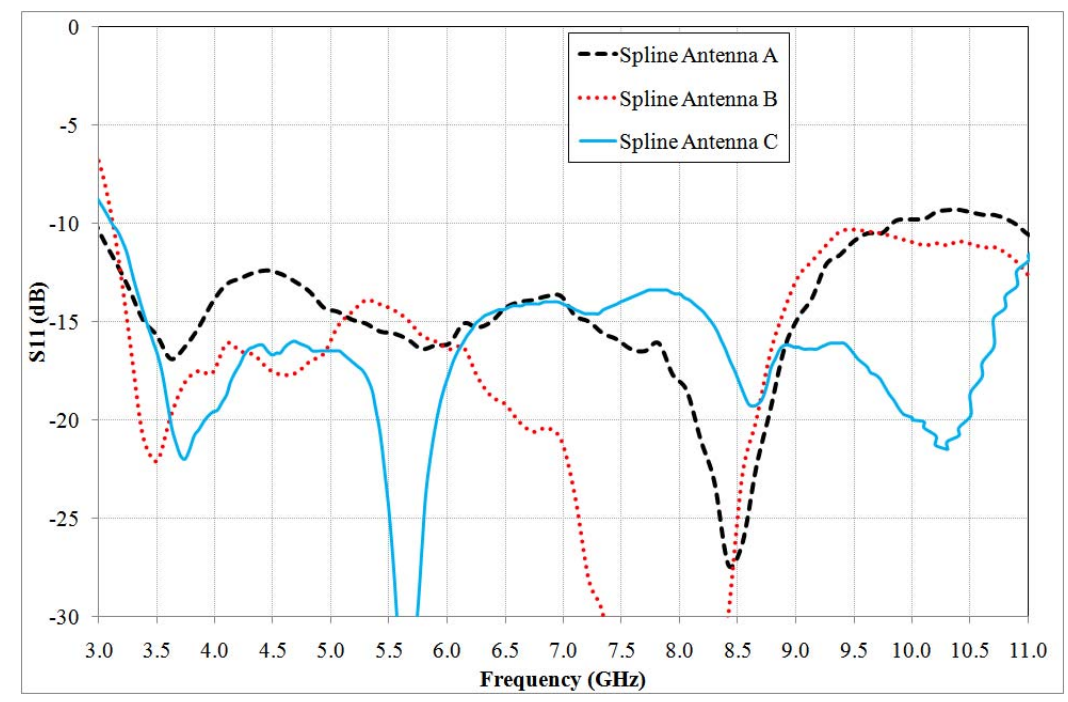

Fig. 8 Spline Antenna S11 Plot

Fig. 8 shows the good matched impedance in the antennas across the Bands A, B and $\mathrm{C}$. The smoothness of Antenna $\mathrm{C}$ and the increasing VSWR ratio in Antenna A in Band D correspond with the group delay performance plots.

\section{Discussion}

The understanding of three, similarly shaped, Bézier-spline UWB antennas is extended by the analysis of their group delay patterns in their azimuth planes. Using a basic set simultanous equations, the individual performance of each is extracted from the phase measurements of three paired combinations. The antennas exhibit good performance in the US region UWB Bands A, B \& C.

\section{References}

[1] M. John and M.J. Ammann, "Spline Based Geometry for Printed UWB Antenna Design," IEEE AP-S International Symposium on Antennas and Propagation, Vol. 1, No. 1, pp. 761-764, Honolulu, Hawai'i, USA, $10 / 06 / 2007$.

[2] B. Allen (Editor) et al, "Ultra Wideband Antennas and Propagation for Communications, Radar and Imaging," John Wiley \& Sons Inc, ISBN 978-0470-03255-8, pp. 160 and pp. 204

[3] C.A. Balanis, "Antenna Theory Analysis and Design," Wiley, $2^{\text {nd }}$ Edition ISBN-13: 978-0471592686, pp 867 